\title{
EVOLUTION OF UWB SLOTTED C SHAPED MONOPOLE ANTENNA FOR COGNITIVE RADIO APPLICATIONS
}

\author{
Prof.M.S.Narlawar ${ }^{1}$, Dr.S.L.Badjate ${ }^{2}$ \\ Dept of Electronics \&Telecommunication Engg, Y.C.C.E, Wanadongri, Nagpur, India ${ }^{1}$ \\ S. B. Jain Institute of Technology, Management \& Research, Nagpur, India ${ }^{2}$
}

\begin{abstract}
The proposed antenna designed specifically for Cognitive radio applications consists of a circular monopole which is evolved into the $\mathrm{C}$ shaped slotted monopole by a systematic process. The evolution of antenna is detailed. The evolved geometry enhances the gain with still good value of bandwidth. This ultra-wideband sensing antenna covers the spectrum from $4.305 \mathrm{GHz}-12.73 \mathrm{GHz}$ [8.428GHz] with a gain of $5.47 \mathrm{dBi}$ as against $10.56 \mathrm{GHz}$ bandwidth of plane circular monopole with a gain of $2.17 \mathrm{dBi}$. Simulated results are presented and find in good agreement with the expected results. This antenna with slight modification can also be used as UWB antenna working in the range of $3.1 \mathrm{GHz}$ to $10.6 \mathrm{GHZ}$.
\end{abstract}

Index Terms: Cognitive Radio, Frequency Reconfigurable, C shaped monopole, UWB Antenna

\section{INTRODUCTION}

The emerging feature-rich and high-data-rate wireless In the future, it is suggested that the spectrum will be applications have resulted in an increasing demand on deregulated and cognitive radios could operate in any radio spectrum. The scarcity of the spectrum and the frequency band within the available spectrum. To this end, inefficiency in its usage, as caused by the current radio CRs must sense the spectrum to find a suitable frequency spectrum regulations, necessitate the development of new band to operate in, and then use it to transmit and receive dynamic spectrum allocation policies to better exploit the data. While there is no agreed scheme for the operation existing spectrum. The current spectrum allocation and the sensing modes in cognitive radios yet, one regulations assign specific bands to particular services, possibility involve having an antenna with its front-end and grant licensed band access to licensed users only. used for continuous sensing and another antenna with its Cognitive Radio (CR) [1] is expected to revolutionize the front-end for the operation. To make sensing of the whole way spectrum is allocated. In a CR network following the spectrum quick, it is suggested that the sensing antenna hierarchical access model [2], the intelligent radio part could be very wideband and the front-end would perform allows unlicensed users (secondary users) to access the frequency subdivision, scanning and filtering to spectrum bands licensed to primary users, while avoiding achieve a convenient noise level for measuring the interference with them. According to the Federal interference. It is also suggested that the communicating Communications Commission (FCC), a cognitive radio is antenna should be narrowband to help filter out-of-band "a radio that can change its transmitter parameters based signals.

on interaction with the environment in which it operates". The proposed UWB antenna is based on a disc monopole, Thus, in cognitive radio system, we need the capability to because this is the radiator shape that is most commonly sense the spectrum ("sensing" antenna), and communicate used for UWB communication systems due to their large ("reconfigurable communicating" antenna).Thus Cognitive radio is a communications system that can change its parameters based on interaction with the environment in which it operates [3], providing the capability to select and use the best available channel or share the spectrum in an opportunistic manner. One of the most novel features of the transceiver for a cognitive radio system is the ability of sensing and using various bands of interest which requires specific hardware technologies such as antennas, which can work efficiently in different bands. Sensing the environment may involve the measurement of the communications traffic and interference across a large part of the electromagnetic spectrum. The radio will also have knowledge of the intentions of its user, to enable it to match its searches to the needs of the user. 


\section{OBJECTIVE}

The objective of this paper is to design a sensing antenna for cognitive radio applications which can span over a wide band width from around $4 \mathrm{GHz}$ to $12 \mathrm{GHz}$ and good gain of about $5 \mathrm{~dB}$. The antenna for this sensing application should also be omni directional. To evaluate the performance of this compact size antenna several factors need to be considered viz. Input Impedance, VSWR, Return loss, bandwidth, directivity, polarization, gain, radiation pattern etc.

Thus, theoretically it is expected that the antenna should have

1. VSWR in the range $1<\mathrm{V}<2$

2. Return loss less than $-10 \mathrm{~dB}$

3. High gain

4. Omni-directional radiation pattern

5. Large Bandwidth for sensing the spectrum

\section{DESIGN OF ANTENNA}

The disc monopole is shown in Figure. 1. As mentioned above, the geometry of the proposed UWB antenna is based on a disc monopole antenna, which was designed according to [5], where an antenna of size $\mathrm{W}=50 \mathrm{~mm}$ by $\mathrm{L}=60 \mathrm{~mm}$ is obtained, with a disc of radius $r=12 \mathrm{~mm}$, a microstrip feed of dimensions $\mathrm{W}_{1}=2.6 \mathrm{~mm}$ by $\mathrm{L}_{1}=20$ $\mathrm{mm}$, and a ground plane of size $\mathrm{W}_{2}=50 \mathrm{~mm}$ by $\mathrm{L}_{2}=$ $20 \mathrm{~mm}$ as detailed in Table1 is designed. The antenna is designed with a radius of $r$ and a $50 \Omega$ microstrip feed line which is printed on the same side of the FR4 (Flame Resistant 4) substrate with the substrate thickness of $h=1.6 \mathrm{~mm}$ and relative permittivity of 4.4 .The ground plane used is a partial ground plane whose dimensions are optimised to a length of $20 \mathrm{~mm}$. The simulation is carried out by using an e.m.design tool cad-feko.

The present antenna is mismatched at lower frequencies which are of interest in cognitive radio applications, so to overcome this limitation, elliptical slots are introduced around the rim of the circular disc. This technique was introduced in order to modify the current flow on the patch without abrupt changes, obtaining an improvement in the impedance matching at lower frequencies. And in order to enhance the impedance matching at higher frequencies, and to get the maximum bandwidth, the circular disc monopole antenna is modified into a ring shaped monopole and from ring shaped monopole to $\mathrm{C}$ shaped monopole which shows marginal improvement in gain and overall performance.

This evolution of antenna from disc monopole to ring monopole, ring monopole to slotted ring monopole and slotted ring monopole to $\mathrm{c}$ shaped slotted monopole has shown improvement in terms of gain and substantial reduction in copper area for the patch with still a good bandwidth. The size of the patch can also be reduced and the antenna can be modified to work in the UWB range.

In the process of designing the disc shaped monopole different dimensions like r, L1 are calculated by standard formulae as described below, while rest of the parameters like L, W, L2, h etc have been optimized after following extensive parametric analysis. In the process of evolution

also a rigorous parametric analysis is followed at every stage of design.

The radius of the circle is obtained from the equation,

$r=1.8412 v_{0} / 2 \pi f_{r}$

where, $V o$ is the velocity of EM waves

$=3 e 10 \mathrm{~cm} / \mathrm{sec}$ or $3 e 11 \mathrm{~mm} / \mathrm{sec}$

$f_{r}$ is the resonant (center) frequency $(3.49 \mathrm{GHz})$

$\varepsilon_{r}$ is the dielectric constant $=4.4$

Therefore, $r=12 \mathbf{m m}$

The length of the patch is given by,

$L_{1}=\lambda / 4$

where, $\lambda=c / f=3 e 8 / 3.5 e 9=85.89 \mathrm{~mm}$

Therefore, $\boldsymbol{L} \mathbf{1}=\mathbf{2 0 . 3} \mathbf{~ m m}$

TABLE I

DESIGN PARAMETERS OF PROPOSED ANTENNA

\begin{tabular}{|c|c|}
\hline Parameters & Value $[\mathbf{m m}]$ \\
\hline L & 60 \\
\hline W & 50 \\
\hline W1 & 2.6 \\
\hline L1 & 20.3 \\
\hline L2 & 20 \\
\hline W2 & 50 \\
\hline r & 12 \\
\hline h & 0.3 \\
\hline
\end{tabular}

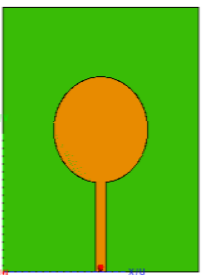

a:front view

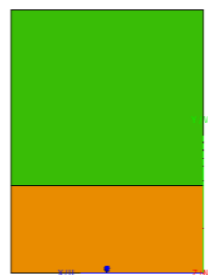

b:bottom view

Fig.1:Geometry of Disc Monopole Antenna

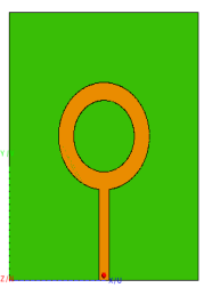

a:front view

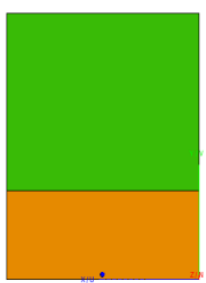

b:bottom view
Fig.2:Geometry of Ring shaped Monopole Antenna

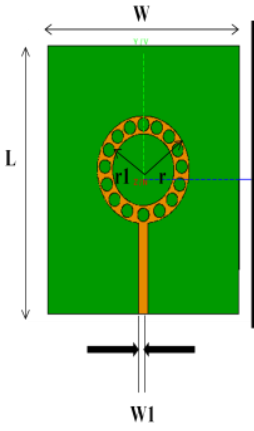

Fig a:front view

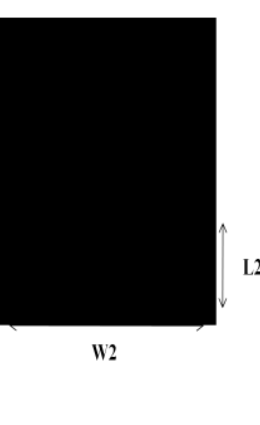

b:bottom view
Fig.3:Geometry of Slotted Ring shaped Monopole Antenna 


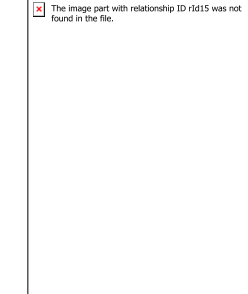

a:front view

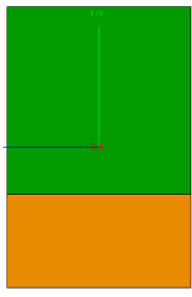

b:bottom view
Fig.4:Geometry of C shaped slotted Monopole Antenna

\section{RESULTS \& DISCUSSION}

The simulated results of the proposed UWB antenna are presented in Fig.5 to Fig 21. The proposed C shaped monopole antenna shows a bandwidth from 3.857 to 11.98 $\mathrm{GHz}$ in which the return loss is below -10db. This proves to be an excellent antenna for cognitive radio applications because it has a good impedance matching for the whole band of interest.

The impedance vs frequency plots of different geometries from disc monopole to $\mathrm{C}$ shaped slotted monopole shows impedance close to $50 \Omega$ which shows a good impedance match with the $50 \Omega$ impedance of the transmission line. This is clearly visible in the plot from Fig.9 to Fig. 12 and from Table 2 as well. The return loss plots of the various geometries shows a wide bandwidth which is an essential requirement of the sensing antenna which is very clear from the plot shown in Fig.5 to Fig.8 and Table2.The return loss plot covers an UWB range in the first geometry but slightly shifted from UWB range in other cases which can be modified easily by properly adjusting the parameters. The return loss plot of ring monopole and slotted ring monopole shows clear cut improvement in bandwidth due to due to change in current distribution with the incorporation of slots of appropriate shape and size at appropriate locations. The cut in the slotted ring at appropriate location and of appropriate size is made by observing surface current distribution. VSWR plot shown in Fig.13 to Fig.16 shows the conformity to the results obtained from the return loss because the return loss of $9.5 \mathrm{db}$ corresponds to the VSWR of 2 which corresponds to $90 \%$ transmission and $10 \%$ reflection of power. The radiation pattern plots shown from Fig.17 to Fig.20 shows almost omnidirectional radiation pattern as per the requirement of sensing antenna. The plot also shows a clear cut improvement in gain from disc monopole $(2.17 \mathrm{dBi})$ to ring monopole $(3.84 \mathrm{dBi})$, ring monopole to slotted ring monopole ( $4 \mathrm{dBi})$ and slotted ring monopole to ' $\mathrm{C}$ ' shaped slotted monopole $(5.47 \mathrm{dBi})$.

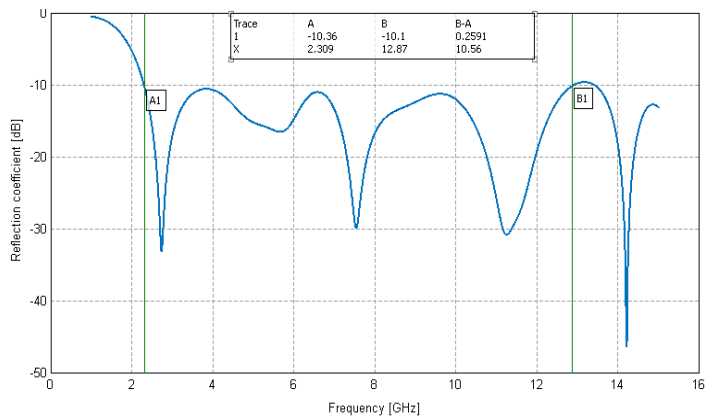

Fig.5:Return loss plot of Disc Monopole Antenna

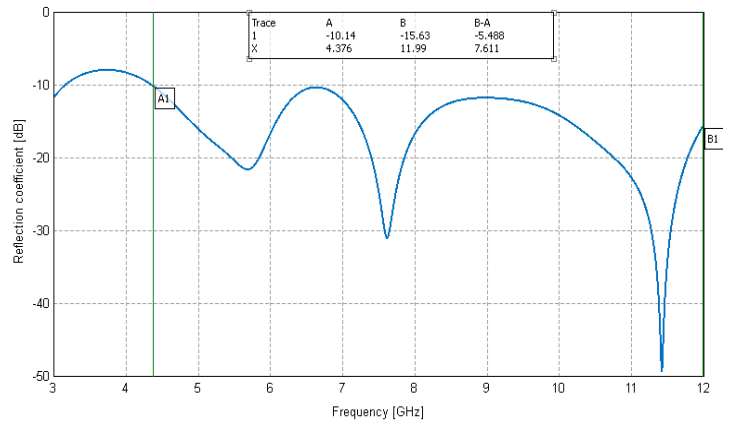

Fig.6:Return loss plot of Ring shaped Monopole Antenna

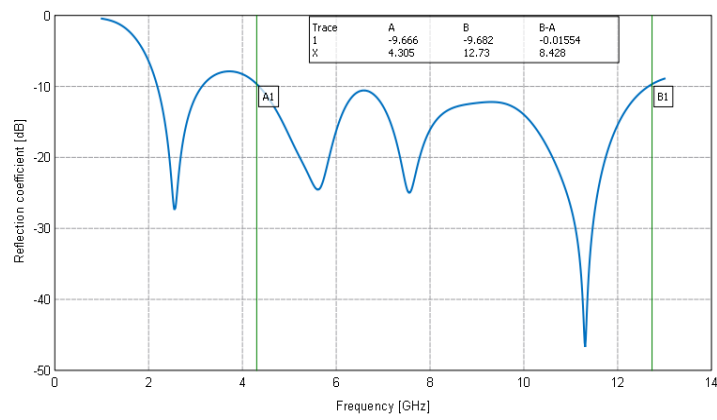

Fig 7: Return loss plot of the Slotted Ring shaped Monopole Antenna.

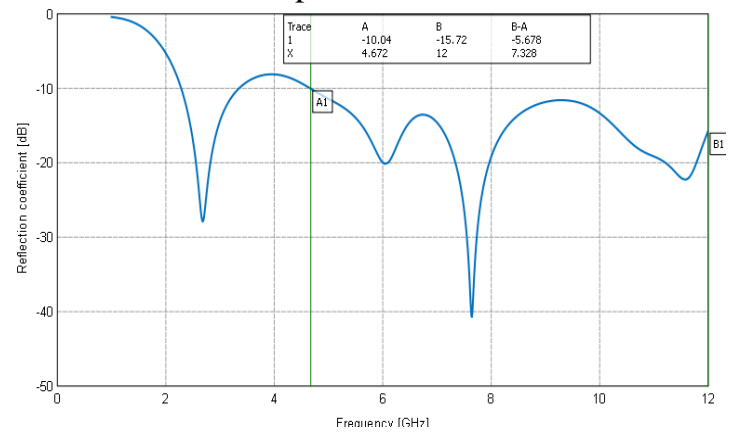

Fig 8: Return loss plot of C shaped Monopole Antenna.

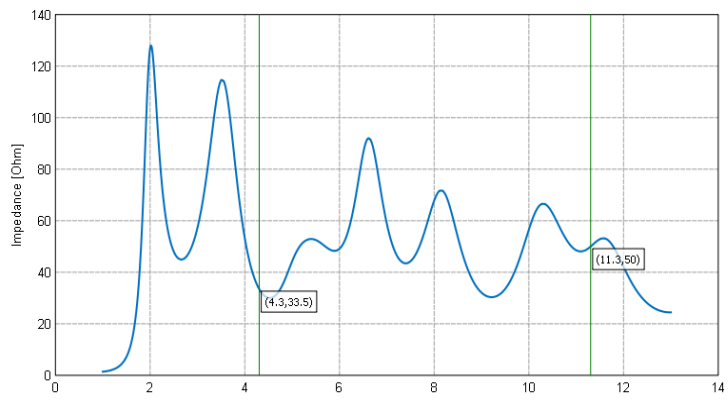

Fig. 9: Impedance plot of Disc Monopole Antenna

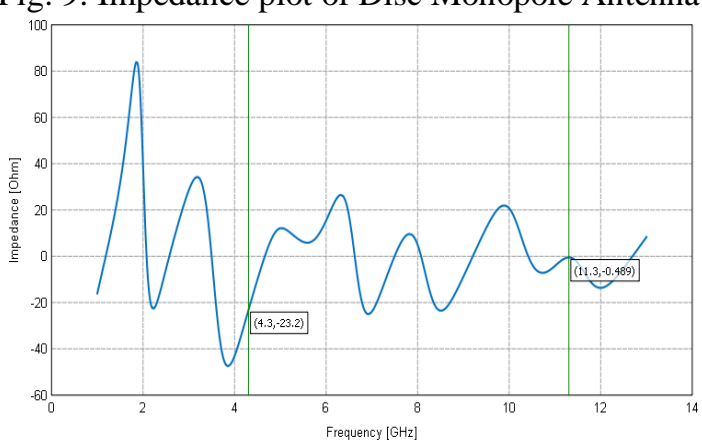


INTERNATIONAL JOURNAL OF INNOVATIVE RESEARCH IN ELECTRICAL, ELECTRONICS, INSTRUMENTATION AND CONTROL ENGINEERING Vol. 2, Issue 11, November 2014

Fig 10: Impedance plot of Ring monopole Antenna

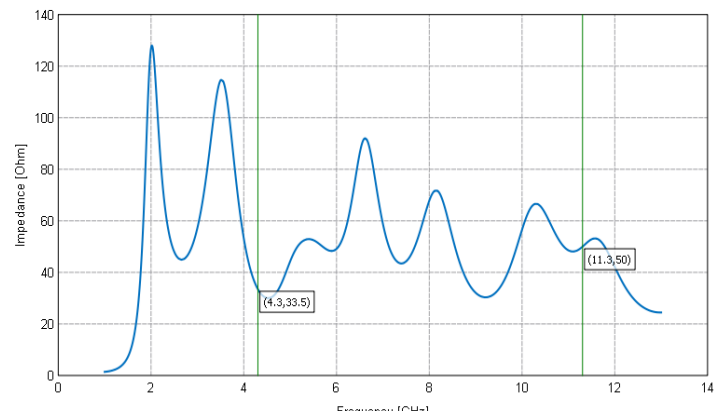

Fig. 11: Impedance plot of slotted Ring monopole Antenna

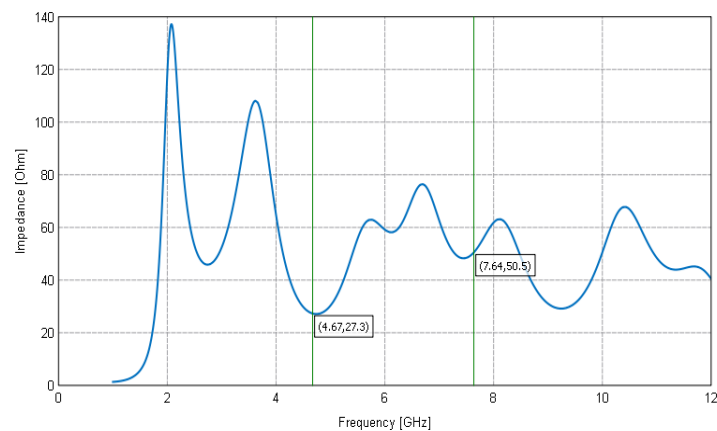

Fig.12: Impedance plot of C shaped slotted monopole Antenna

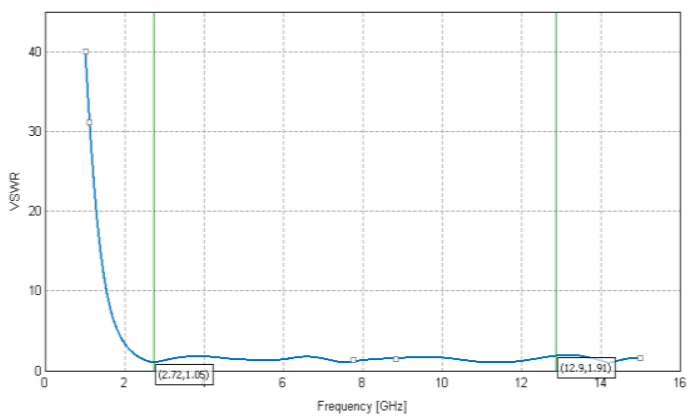

Fig.13:VSWR plot of Disc Monopole Antenna

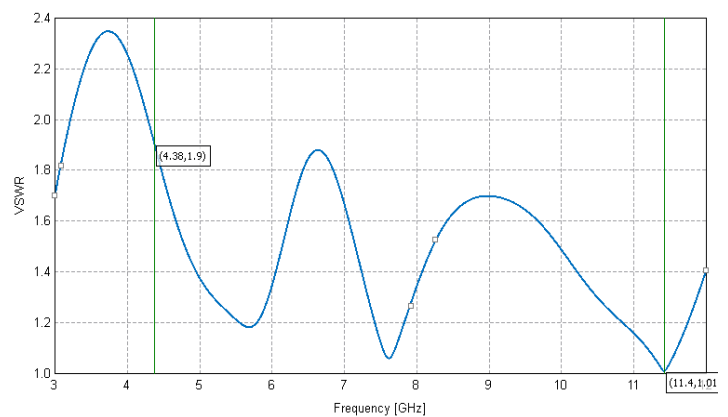

Fig.14:VSWR plot of Ring Monopole Antenna

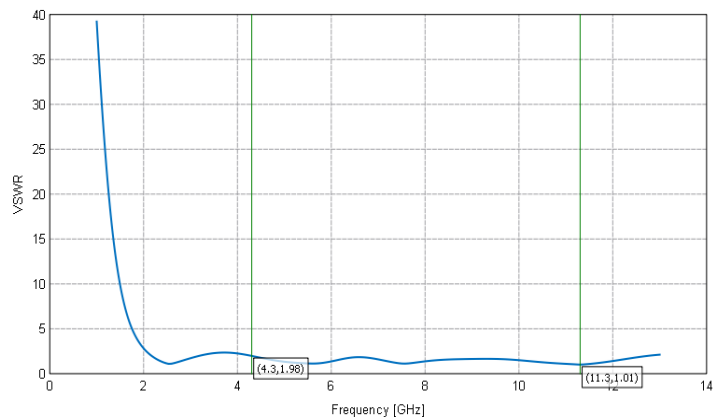

Fig.15: VSWR plot of Slotted Ring Monopole Antenna

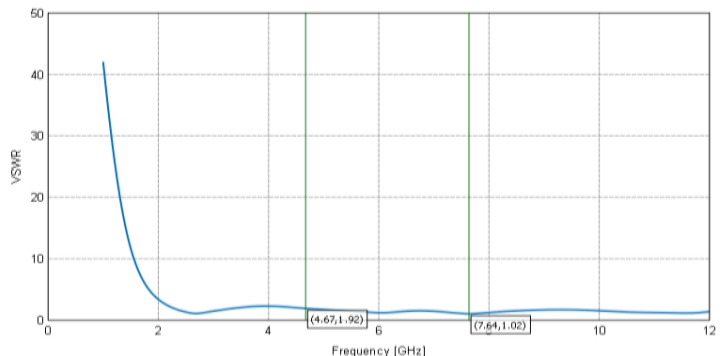

Fig.16: VSWR plot of C shaped slotted monopole Antenna

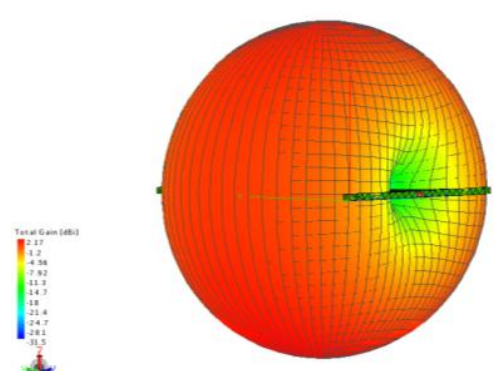

Fig.17: Radiation pattern of Disc Monopole Antenna

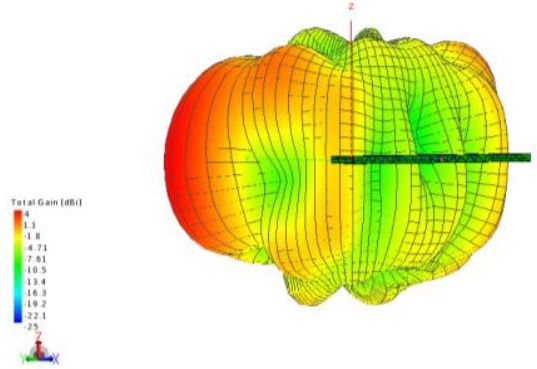

Fig.18: Radiation pattern of Ring Monopole Antenna

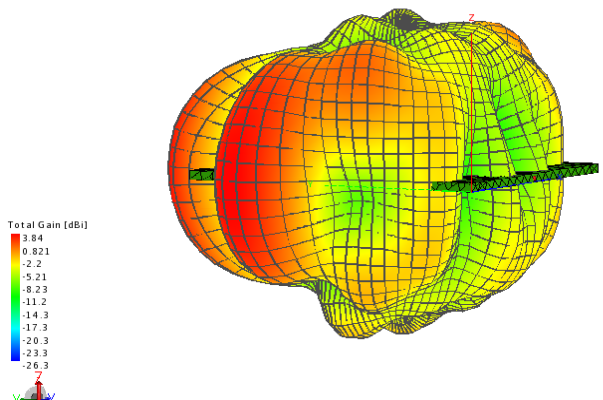

Fig. 19: Radiation pattern of Slotted Ring Monopole Antenna 

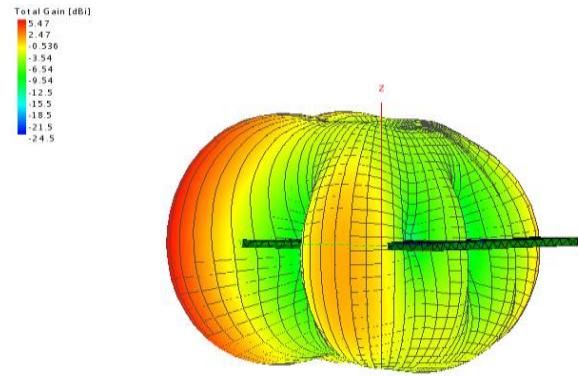

Fig.20: The radiation pattern of C shaped Slotted Monopole

Antenna

TABLE2

COMPARISON OF VARIOUS ANTENNAS IN THE PROCESS OF EVOLUTION

\begin{tabular}{|c|c|c|c|c|}
\hline SNo & $\begin{array}{c}\text { Type of } \\
\text { Antenna }\end{array}$ & $\begin{array}{c}\text { Input } \\
\text { Impedance } \\
\text { at fr }\end{array}$ & $\begin{array}{c}\text { Impedance } \\
\text { Bandwidth }\end{array}$ & $\begin{array}{c}\text { Gain } \\
\text { [dBi] }\end{array}$ \\
\hline 1. & $\begin{array}{c}\text { Disc } \\
\text { Monopole }\end{array}$ & 52.3 & $10.56 \mathrm{GHz}$ & 2.17 \\
\hline 2. & $\begin{array}{c}\text { Ring } \\
\text { Monopole }\end{array}$ & 50 & $8.691 \mathrm{GHz}$ & 3.84 \\
\hline 3. & $\begin{array}{c}\text { slotted ring } \\
\text { Monopole }\end{array}$ & 50 & $8.468 \mathrm{GHz}$ & 4.00 \\
\hline 4. & $\begin{array}{c}\text { C shaped } \\
\text { slotted } \\
\text { Monopole }\end{array}$ & 50.5 & $7.238 \mathrm{GHz}$ & 5.47 \\
\hline
\end{tabular}

\section{CONCLUSION \& FUTURE SCOPE}

The Disc Monopole Antenna is evolved into C shaped slotted monopole antenna by inserting elliptical slots in the rim, which improves the performance of the antenna. The antenna is simulated using the simulation tool CADFEKO ${ }^{\circledR}$. The observed results are tabulated above and are found to be in close agreement with the theoretically expected values. This antenna can be used as a sensing antenna in Cognitive Radio applications due to its large bandwidth, good gain and omni directional radiation pattern.

Its usability in Cognitive Radio systems can be enhanced by incorporating a narrowband reconfigurable antenna in the same antenna structure which can make the communication of secondary users possible. This antenna which is the combination of sensing and reconfigurable antenna will make it a complete antenna that can be used in cognitive radio applications. This can be achieved in several ways, but the care is required to be taken that coupling between the two antenna ports must be within acceptable limits.

The antenna with slight modifications in the design can be operated in UWB i.e from 3.1to $10.6 \mathrm{GHz}$. This antenna can be used for UWB applications as well as in cognitive radio application with Underlay approach i.e. working in the presence of primary user.

\section{REFERENCES}

[1] J. Mitola and G. Q. Maguire, "Cognitive radio: making software radios more personal," IEEE Pers. Commun., vol. 6, no. 4, pp. 1318, Aug.1999.

[2] K.-C. Chen and R. Prasad, Cognitive Radio Networks, John Wiley \& Sons, West Sussex, United Kingdom, 2009.

[3]Akyildiz, I. F., W. Y. Lee, M. C. Vuran, and S. Mohanty, "Next generation/dynamic spectrum access/cognitive radio wireless networks: A survey," Comp. Networks J., Vol. 50, 2127-2159.Sep. 2006.

[4] Federal Communication Commission, "Revision of part 15 of the commission's rules regarding ultra-wideband transmission systems", First Report and Order, ET Docket 98-153, FCC 02-48, Feb.2002.

[5] L. Yang, G.B. Giannakis, "Ultra-Wideband Communications”, IEEE signal processing magazine, Vol.21, No.6, pp.26-54, Nov.2004

[6] Liang, J., C. C. Chiau, X. Chen, and C. G. Parini, "Study of a printed circular disc monopole antenna for UWB systems,"IEEE Transactions on Antennas and Propagation, Vol. 53, No. 11, 35003504, Nov. 2005.

[7] F. Ghanem, P.S. Hall and J.R. Kelly, "Two port frequency reconfigurable antenna for cognitive radios", ELECTRONICS LETTERS 21st May 2009 Vol. 45 No. 11

[8] "Report of the Spectrum Efficiency Working Group," FCC Spectrum Policy Task Force, FCC, Tech. Rep., 2002.

[9] C.A. Balanis, "Modern Antenna Handbook", John Wiley \& Sons, Inc., New York.2008.

[10] Kazimierz Siwiak and Debra McKeown, John Wiley \& Sons, Ultra-Wideband Radio Technology", Inc., NewYork.2004.

[11]. "A Reconfigurable Cognitive Radio Antenna Design", M. AlHusseini, Youssef Tawk, C. G. Christodoulo, K. Y. Kabalan, A. El Hajj, ECE Department, American University of Beirut, Beirut 1107 2002, Lebanon.

[12]. "Cognitive Radio: UWB Integration and Related Antenna Design", Mohammed Al- Husseini, Karim Y. Kabalan, Ali ElHajj and Christos G.Christodoulou, American University of Beirut, Beirut 1107 2020, Lebanon.

[13]. "Performance Study on Modern Ultra Wideband Monopole Antennas", Abdelhalim Mohamed and Lotfollah Shafai, University of Manitoba, Canada.

[14]. "Antenna Study and Design for Ultra Wideband Communication Applications", Jianxin Liang, Department of Electronic Engineering, Queen Mary, University of London, United Kingdom, July 2006.

[15]. "Ultra-width Band Antenna Design", Leung Koon Hei, Department of Electronic Engineering, The Chinese University of Hong Kong, May 2007.

[16]. "International Journal of Antennas and Propagation: UltraWideband Antennas", Guest Editors: James Becker, Dejan Filipovic, Hans Schantz, and Seong- Youp Suh.

[17]. "Compact Antennas for UWB Applications",Taeyoung Yang, Seong-Youp Suh, Randall Nealy, William A. Davis, and Warren L. Stutzman, Virginia Tech Antenna Group, Bradley Dept. of Elec. \& Comp. Engineering Virginia Tech, Blacksburg, VA.

[18]. "Antenna Design for Ultra Wideband Radio", Johnna Powell, New Mexico State University, 2001 